\title{
Surface roughness condition of field-aged polymer insulators at different installation area
}

\author{
A. Din ${ }^{1}$, M. A. M. Piah $^{2}$, A. R. Abdullah ${ }^{3}$, N. F. Kasri ${ }^{4}$ \\ ${ }^{1,3}$ Universiti Teknikal Malaysia Melaka, Malaysia \\ ${ }^{2,4}$ Universiti Teknologi Malaysia \& Institute of High Voltage and High Current, Malaysia
}

\begin{tabular}{l}
\hline Article Info \\
\hline Article history: \\
Received Oct 13, 2018 \\
Revised Feb 16, 2019 \\
Accepted Mar 29, 2019 \\
\hline
\end{tabular}

\section{Keywords:}

Correlation analysis

Environmental stress

Field-aged insulator

Insulator degradation

Surface roughness

\begin{abstract}
This paper presents surface degradation assessment based on surface roughness condition for various field-aged high voltage polymer insulators that were installed at different locations. The measurement of arithmetical mean surface roughness is done, and statistical analysis is implemented in this study. Three groups of insulators labeled as 6 years, 12 years, 18 years, and with their respective controlled samples are tested using a surface roughness tester. Data measurements from the testing are analyzed in conjunction with visual observation to investigate an indication of surface degradation within the groups. Further statistical analysis is applied for the comparison of the surface roughness conditions. In order to observe the environmental stress factors that will affect the roughness condition, within the installation area, the virtual three-dimensional mapping program represented the Earth based on satellite imagery is utilized. The correlation analysis on all that three groups has indicated the positive outcomes with the roughness increased with respect to the age of insulator that located in quite similar environmental stress conditions. Regardless of the age of an insulator, the degradation due to surface roughness condition can be used to indicate what levels of environmental stress around the installation area have.
\end{abstract}

Copyright $@ 2019$ Institute of Advanced Engineering and Science. All rights reserved.

\section{Corresponding Author:}

M. A. M. Piah,

Institute of High Voltage and High Current,

School of Electrical Engineering, Faculty of Engineering,

Universiti Teknologi Malaysia, 81310 Johor Bahru, Johor, Malaysia.

Email: fendi@utm.my

\section{INTRODUCTION}

In line with the insulation material technology development, the outdoor ceramic type insulator is gradually replaced by the outdoor polymer type insulator due to some advantages of the polymer material such as lightweight structure which gives weight reduction up to $90 \%$ [1], easy to install [2] and uniqueness of its hydrophobicity property [3]. However, in service, this organic based insulator still suffer degradation that was affected by the combination of multiple elements such as mechanical, electrical and thermal stresses during its operation [4]. In addition, the degradation will be further propagated due to an environmental stress such as ultra-violet, heat, condensation and acidic compound that was imposed naturally on its surface [5]. It is inevitable factor which depends on the local climate and pollution condition that was experienced by the outdoor insulators at the field of service. These multiple stresses vigorously accelerate degradation that will cause surface tracking [1], weight loss or erosion [6], loss of surface hydrophobicity [7], partial arcs discharge, and increase an electrical leakage current (LC) [8] or complete failure [9].

With regards to the high risk impact that potentially may occur due to degradation, researchers worldwide have explored various evaluation and analysis methods in order to minimize and overcome this issue. These evaluation and analysis covering on physical evaluation such as insulator surface roughness, chemical properties [10], [11] and electrical properties for example a leakage current analysis. 
Insulator surface roughness [12], [13] and LC analysis [14], [15] are becoming common method to be applied.

This study is intended to investigate the polymer insulator degradation conditions by measuring one of the degradation indication parameter focusing on the insulator surface roughness. The testing material would be the three units of field-aged surge arrester's housing insulator which was acquired from Tenaga Nasional Berhad (TNB), the Malaysian national power company. These field-aged insulators were originatedly removed from transmission main intake (Pencawang Masuk Utama, PMU) in Pagoh, Simpang Renggam and Plentong power substation located along the coast in the state of Johor, Malaysia. These insulators have been in field service within variety of years.

\section{BACKGROUND THEORY}

Physical evaluation is the preliminary process of investigating the insulator degradation performance. Among the common analysis that emerge under this evaluation are surface roughness and visual observation.

\subsection{Definition of Surface Roughness}

Surface roughness will deviate the texture of the surface in the direction of the normal vector of a real surface from its original form. There is directly proportional relationship between deviation and roughness level in which if these deviations are large, the surface is rough; if they are small, the surface is smooth [16].

The parameter measured for surface roughness is an arithmetical mean surface roughness $\left(R_{a}\right)$. It is defined as the average absolute deviation of the roughness irregularities from the mean line over one sampling length as shown in Figure 1 . The unit of $R_{a}$ that commonly used is micrometer $(\mu \mathrm{m})$ or microinch ( $\mu$ in). In general, since there is no specific threshold values for the measurement, the roughness condition will be used as the comparison purposes [17]. For instance, in one case study whereby an accelerated test is carried out and the researchers have made the conclusion that, for the ethylene propylene diene monomeraluminium trihydrates (EPDM-ATH) surge arrester, the value of $R_{a}$ has doubled from the original value when 1000 hours test have been performed [12].

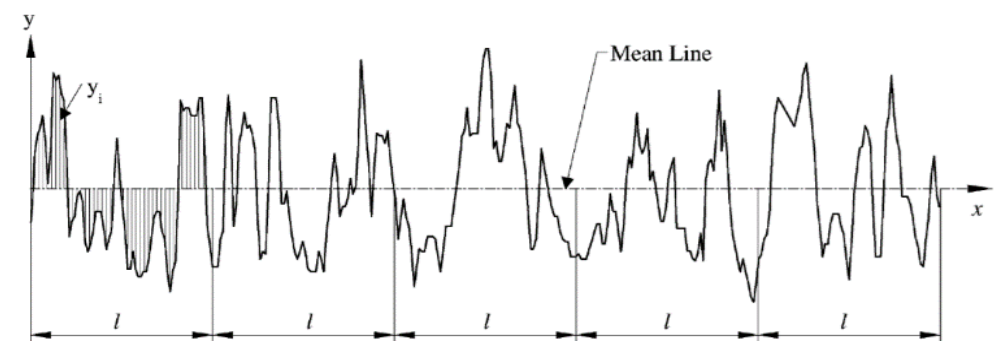

Figure 1. Definition of the arithmetical mean surface roughness [18]

The general mathematical equation and its digital implementation of the arithmetical mean surface roughness is shown in (1) and (2) respectively.

$$
\begin{aligned}
& R a=\frac{1}{l} \int_{0}^{l}|y(x)| d x \\
& R a=\frac{1}{n} \sum_{i=1}^{n}|y i|
\end{aligned}
$$

Where $l$ is the evaluation sampling length, $y(x)$ is the profile height function, $y_{i}$ is the individual height profile, $n$ is the number of samples along the assessment length of the profile [18].

\subsection{Relationship of $R_{a}$ with Insulator Age and Environmental Stress}

Significantly, considering the identical environmental stress, the higher age of service insulator, the larger $R_{a}$ and porosity of surface insulator will be appeared [13], [19]. This can be described through the loss of the polymer outer layer on the surface, in which it will look like the surface finish of the molding process. As the aging time keep growing, gradually the erosion will cause the outer layer to be invoked due 
to the replacement process. This will make the outer layer of the insulator to be relieved with a layer composed of polymer and exposed fillers. Thus, this condition will cause the roughness value to rise, and will provide much more information regarding on the polymer surface degradation [12].

Meanwhile, the condition of $R_{a}$ will be severe due to the high stress environment regardless of how long it has been employed in the service. The accumulated pollution and dust have contributed to influencing the surface roughness of the insulation, thereby reducing the dielectric performance after a long period of time [13]. This is to be observed with the existence of LC on the surface of EPDM and silicon rubber (SiR) as pollution is not fully removed, even after continuous rain [20].

The influence of low molecular weight (LMW) and the general matrix to provide hydrophobicity are getting lower due the pollutant on the surface. As the consequence, this surface tend to easily harm because of electrical activities such as corona discharges, dry band arcs etc. This circumstance will accelerate the process of erosion, thus making the surface to be roughed much faster. There are cases whereby provided with sufficient time frame, the influence of encapsulation process would also contribute to the surface roughness. This condition is occurred because of the LMW molecules have dispersed into polluting substance and occupied permanently as the composite on the insulator surface [17].

\subsection{Visual Observation}

Visual observation is one of the most commonly used techniques for aging estimation of polymer insulators all over the world [20]. This observation is carried out via bare eye vision to recognize the general condition of insulator surface. Among the properties that to be observed are loss of gloss and discoloration, chalking and deposited contaminated substance on the surface [3]. Initially, the aging insulator will experience the loss of gloss and discoloration. Chalking condition is formed on the surface when a rough and whitish powder appeared due to ultra-violet radiation and electrical activity [21]. When this happens, it permits high volume of accumulated water, thus, further contaminated the surface. Therefore, that deposited contaminated substance can be clearly visualized.

\subsection{Correlation Analysis}

In statistic, a simple linear correlation measures the strength of the linear association between two variables. The relationship between two variables is the correlation coefficient. The value of the correlation coefficient always lies in the range -1 to 1 ; that is $-1 \leq r \leq 1$ where $r$ is the correlation coefficient calculated for sample data. The $r$ is calculated as in (3).

$$
r=\frac{S S_{x y}}{\sqrt{S S_{x x} S S_{y y}}}
$$

Where the sum of squared values of $S S_{x y}, S S_{x x}$ and $S S_{y y}$ are given as in (4), (5) and (6) respectively.

$$
\begin{aligned}
& S S_{x y}=\sum(x-\bar{x})(y-\bar{y}) \\
& S S_{x x}=\sum(x-\bar{x})^{2} \\
& S S_{y y}=\sum(y-\bar{y})^{2}
\end{aligned}
$$

The $x$ and $y$ represent the mean arithmetic surface roughness as variables from two different groups of field-aged insulators that need to be analyzed. The relevant characteristic of correlation between two variables can be made by referring the value of $r$ as in Table 1 [22].

Table 1. Characteristic of Correlation based on Value of $r$

\begin{tabular}{cc}
\hline Value of $r$ & Characteristic of correlation \\
\hline$r$ is positive and close to 1 & A strong positive linear correlation \\
$r$ is positive but close to zero & A weak positive linear correlation \\
\hline
\end{tabular}

\section{RESEARCH METHOD}

The EPDM silicone rubber insulator in the polyvinyl nitrate (PVN) polymer station class surge arrester (SA) is used for testing. The technical details of this SA can be referred to the product datasheet in [23], with their field service information as in Table 2. 
Table 2. Field Service Information of SA

\begin{tabular}{cccc}
\hline \multicolumn{4}{c}{ PVN Polymer Station Class Arrester } \\
ESPTM & silicone consists of compounded silicone oil and EPDM rubber. \\
\hline Year of manufactured & Years of service & Periods of service & Location of installation \\
1997 & $2009-2015$ & 6 years & PMU Pagoh, Johor \\
1997 & $2003-2015$ & 12 years & $P M U$ Plentong, Johor \\
1997 & $1997-2015$ & 18 years & $P M U$ Simpang Renggam, Johor \\
\hline
\end{tabular}

The process of carrying out the surface roughness testing involved several stages. These stages are:

\subsection{Sample Preparation}

(a) SA disassembly: To take out the corona ring and separate out the insulator sheds.

(b) Sample numbered: To number each sample in descending order from 20/20 (top shed) to 1/20 (bottom shed) of the SA.

(c) Visual inspection: To select suitable samples to be tested. The factors to be considered including free from mechanical defect either due to handling or unsuitable manufacturing design. For the controlled samples, two insulator sheds are sorted from the mid-section of the SA while for the field-aged samples, ten pieces are sorted from top, mid and bottom section of the SA.

(d) Controlled sample preparation: To clear out contaminations on the samples using isoprophyl alcohol and rinse with distilled water [24].

(e) Specimen measuring points: To set four different testing points on each sample.

\subsection{Workflow of Testing and Analysis Implementation}

The process of testing and analysis of the samples is represented in Figure 2.

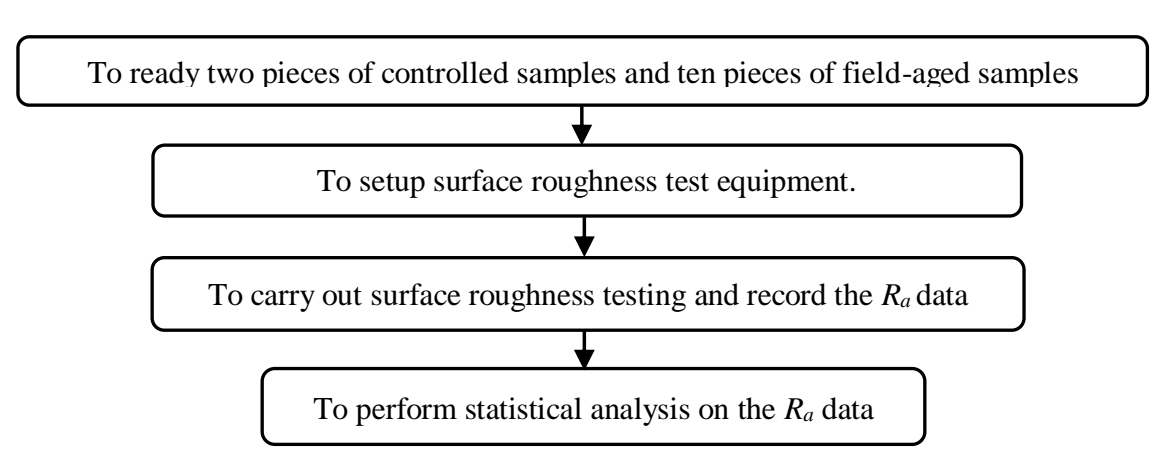

Figure 2. Workflow of sample testing and analysis

\subsection{Test Equipment Setup}

The equipment that has been used is Mitutoyo portable surface roughness tester Surftest SJ-410 Series Model [25]. This equipment consists of several main parts which are data terminal equipment, measuring loop, probe (pickup), stylus and feed device. Prior to the testing, calibration is carried out. In order to have the correct angle configuration between stylus tip and surface of insulator sample, the suitable jig and water leveling tool have to be used. The evaluation sampling length, $l$ is set to $25 \mathrm{~mm}$. Others parameter are set according to ISO1997 standard. The test equipment setup is shown in Figure 3.

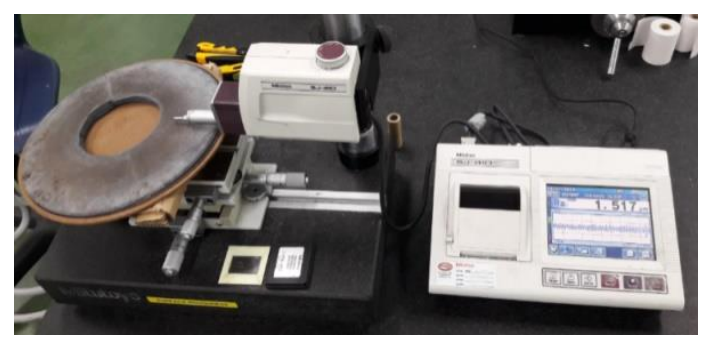

Figure 3. Setup of surface roughness test equipment. 


\section{RESULTS AND ANALYSIS}

At the beginning, the four points of arithmetical mean surface roughness, $R_{a}$ data for each ten fieldaged sample are recorded. Then the sample mean of $R_{a}\left(\bar{R}_{a}\right)$ and sample standard deviation of $R_{a}\left(s R_{a}\right)$ are calculated using the (7) and (8) respectively [22].

sample mean of $R_{a}$ :

$$
\bar{R}_{a}=\frac{\sum R_{a}}{n}
$$

sample standard deviation of $R_{a}$ :

$$
s R_{a}=\sqrt{\frac{\sum R_{a}{ }^{2}-\frac{\left(\sum R_{a}\right)^{2}}{n}}{n-1}}
$$

The sample mean of arithmetical mean surface roughness, $\bar{R}_{a}$ will be recognized as a mean arithmetic surface roughness afterwards. These calculation values are implemented for each sample of three groups field-aged polymer insulator and presented in Table 3. Similar step was repeated on the two controlled samples whereby one of them is chosen as the reference sample. The mean arithmetic surface roughness of controlled sample insulators, $\bar{R}_{a c s}$ and its standard deviation, $s R_{a c s}$ are calculated and shown in Table 4.

Table 3. The Mean Arithmetic Surface Roughness and Standard Deviation for Each Sample of Three Groups Field-Aged Polymer Insulator

\begin{tabular}{ccccccc}
\hline \multirow{2}{*}{ Sample no. } & \multicolumn{3}{c}{ Mean arithmetic surface roughness, $\overline{\boldsymbol{R}}_{a}$ and its standard deviation, $s R_{a}$ of insulators } \\
\cline { 2 - 6 } & \multicolumn{2}{c}{ 6 years field-aged } & \multicolumn{2}{c}{12 years field-aged } & \multicolumn{2}{c}{18 years field-aged } \\
\cline { 2 - 6 } & $\bar{R}_{a-6}(\mu \mathrm{m})$ & $s R_{a-6}$ & $\bar{R}_{a-12}(\mu \mathrm{m})$ & $s R_{a-12}$ & $\bar{R}_{a-18}(\mu \mathrm{m})$ & $s R_{a-18}$ \\
\hline $2 / 20$ & 0.699 & 0.030 & 1.424 & 0.435 & 0.971 & 0.191 \\
$3 / 20$ & 1.052 & 0.128 & 1.559 & 0.097 & 1.188 & 0.223 \\
$5 / 20$ & 0.824 & 0.066 & 1.450 & 0.159 & 0.983 & 0.258 \\
$6 / 20$ & 0.761 & 0.118 & 1.440 & 0.312 & 0.860 & 0.282 \\
$10 / 20$ & 0.921 & 0.101 & 1.518 & 0.242 & 1.190 & 0.251 \\
$11 / 20$ & 0.944 & 0.120 & 1.364 & 0.181 & 1.306 & 0.236 \\
$15 / 20$ & 0.648 & 0.069 & 1.870 & 0.468 & 1.268 & 0.312 \\
$16 / 20$ & 0.634 & 0.054 & 3.810 & 0.790 & 1.009 & 0.378 \\
$19 / 20$ & 1.267 & 0.127 & 1.136 & 0.144 & 1.386 & 0.244 \\
$20 / 20$ & 1.026 & 0.145 & 7.294 & 2.824 & 1.307 & 0.246 \\
\hline
\end{tabular}

Table 4. The Mean Arithmetic Surface Roughness and Standard Deviation for Controlled Sample of Each Three Groups Field-Aged Polymer Insulator

\begin{tabular}{ccccccc}
\hline & \multicolumn{6}{c}{ Mean arithmetic surface roughness, $\bar{R}_{\text {acs }}$ and its standard deviation, $s R_{a c s}$ of controlled sample } \\
insulators
\end{tabular}

As been indicated in Table 4, the value of $\bar{R}_{a c s}$ for every group is different. This indicates that each group had experienced different level of degradation. The 6 years and 18 years field-aged insulator have been installed in different $P M U$ location with quite similar environment which is in a small industrial area. The image of the PMUs surrounding has been captured via Google Earth in 2014 [26].

The histograms in Figure 4 have been plotted using the tabulated data in Table 3 and Table 4. The $\bar{R}_{a c s}$ for each group exhibit smaller value compared to $\bar{R}_{a}$. This situation is as expected due to the contamination layer on the controlled sample surface has been removed. These controlled samples will be used as the reference.

However, as expected the value of $\bar{R}_{a c s-18}$ much larger than $\bar{R}_{a c s-6}$ because it has experienced longer period of field service. The similar characteristic can be observed on the $\bar{R}_{a}$ for ten samples of field-aged insulator that depicted in line chart as shown in Figure 4. As been indicated in the plot of ten samples fieldaged, overall trend variations of $\bar{R}_{a-6}$ and $\bar{R}_{a-18}$ seem to be in the identical pattern. But, the value of $\bar{R}_{a-18}$ is slightly higher, in which it is parallel with results of the reference sample. 


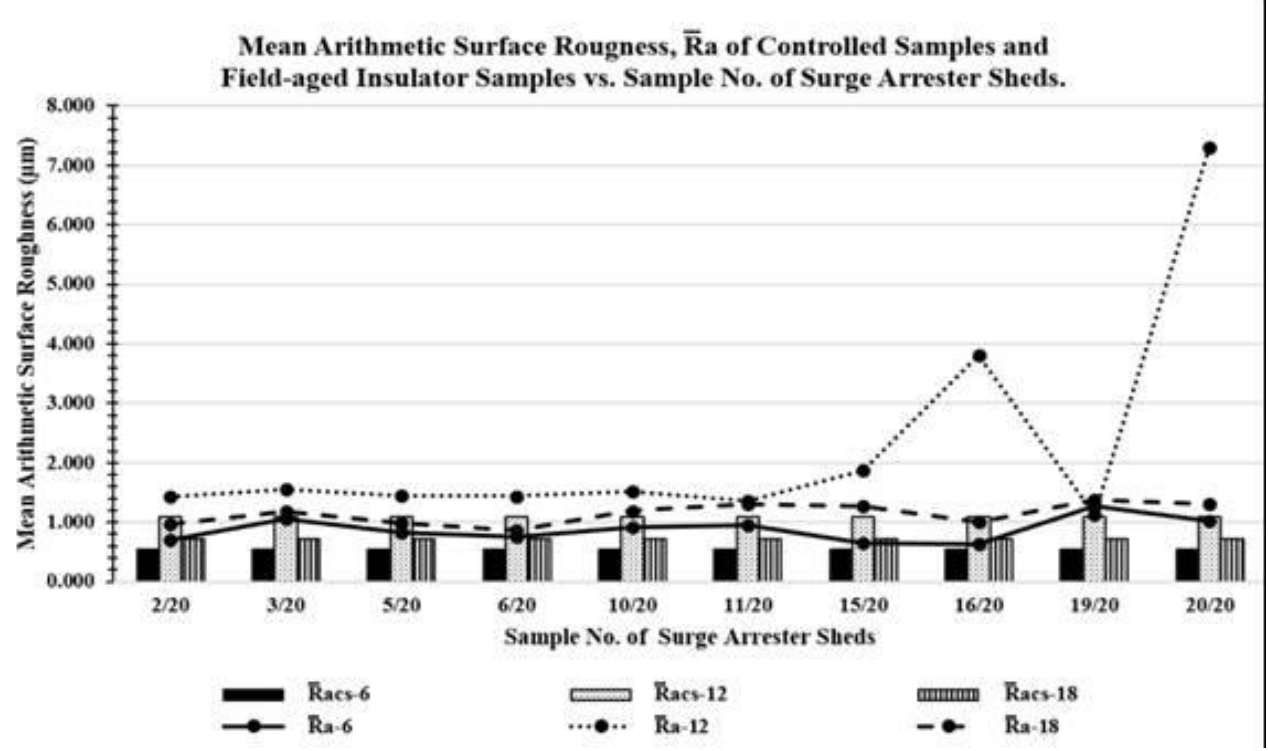

Figure 4. Three different performance based on the mean arithmetic surface roughness of the numbered sheds insulator for the controlled samples and the field-aged insulators

This finding is supported by the correlation analysis results as shown in Table 5. The result of $r_{6-18}$ is positive and close to 1 revealed that there is a strong positive linear correlation between 6 and 18 years fieldaged insulators surface roughness. Instead, the results of $r_{6-12}$ and $r_{12-18}$ were in the positive value but close to zero, which a weak positive linear correlation. Interestingly, by referring to Figure 4, the results of mean arithmetic surface roughness for 12 years, either controlled sample or field-aged sample, most likely have higher value compare to the other two field-aged samples. The difference is so obvious particularly on the shed insulator that was on the top of section, as shown via line chart in Figure 4.

Table 5. Results of correlation analysis for $\bar{R}_{a}$ among field-aged insulator groups.

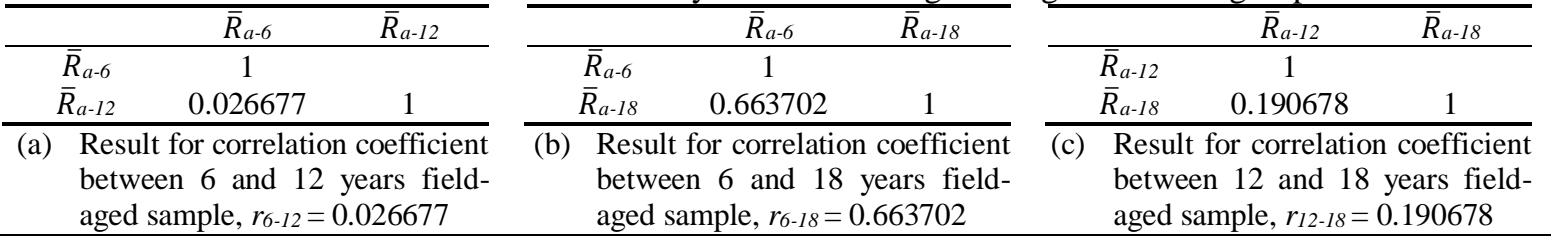

Thus, observation has been done on the actual installation location of this SA. Apparently, via Google Earth image that has been captured in 2014 [26], the PMU Plentong is located in the very high environment stress. Its location was in the well-developed area surrounded by at least three industrial areas with the distance radius approximately $5 \mathrm{~km}$. Besides that, it is also an area with high population, newly developed town and residences. All these are as an indicator of very high environment stress which has affected the severe degradation on this 12-year field-aged insulator.

Figure 5 indicates the difference between the insulator surface appearance among the insulator groups. Through visual observation, the condition of the 12-year field-aged insulator is seemed most degraded, by evaluating the existence of degradation influenced by environmental contamination. It is not only from the loss of gloss, but also via chalking condition, added-on by the contaminated substance deposited permanently on the surface. This can be seen clearly in Figure 5 (e) and (h). Figure 5 (a), (b) and (c) show the controlled samples as a reference for each group. When a comparison is made between fieldaged insulator and controlled samples respectively, all field-aged insulator displaying discoloration and chalking condition has emerged. This has proved that the material aging of the EPDM rubber has contributed to a degraded performance of the insulators under contaminated conditions and various factors of environmental stresses. 


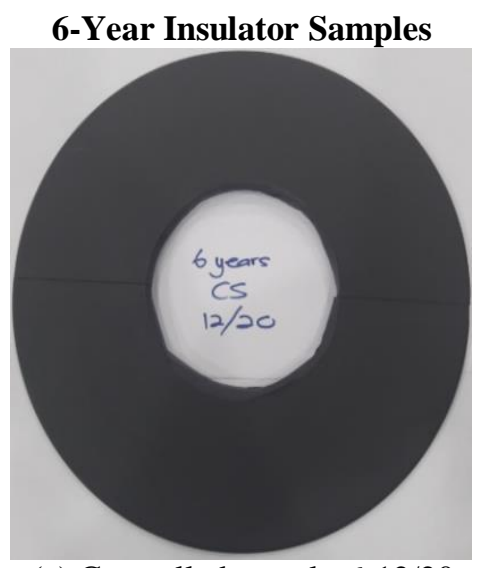

(a) Controlled sample-6-12/20

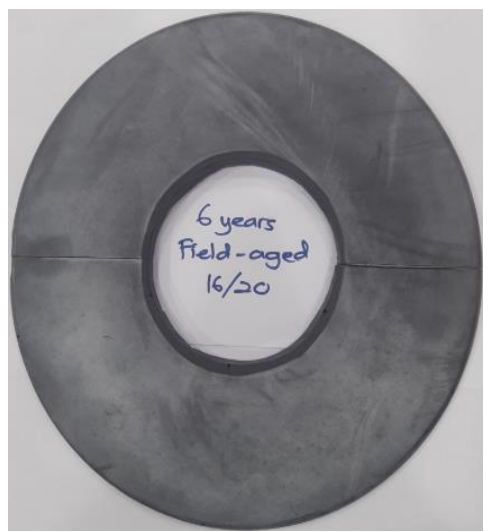

(d) Field-aged-6-16/20

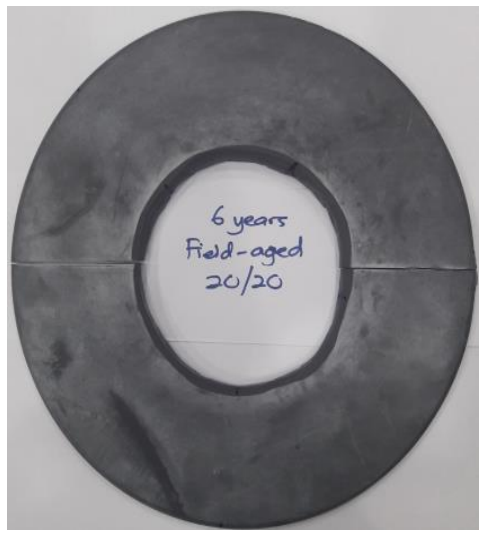

(g) Field-aged-6-20/20

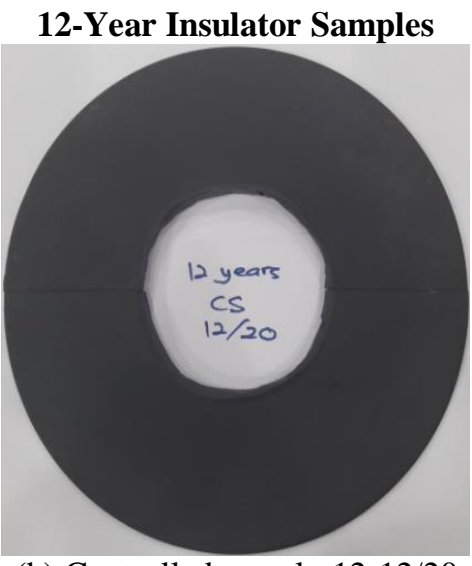

(b) Controlled sample-12-12/20

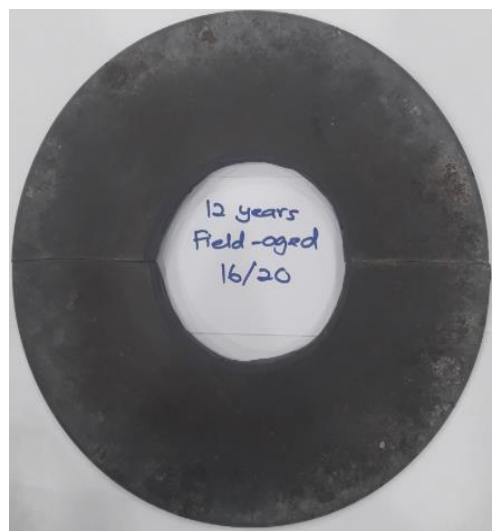

(e) Field-aged-12-16/20

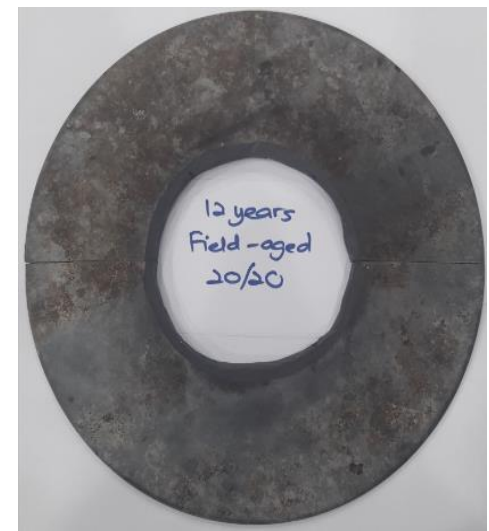

(h) Field-aged-12-20/20

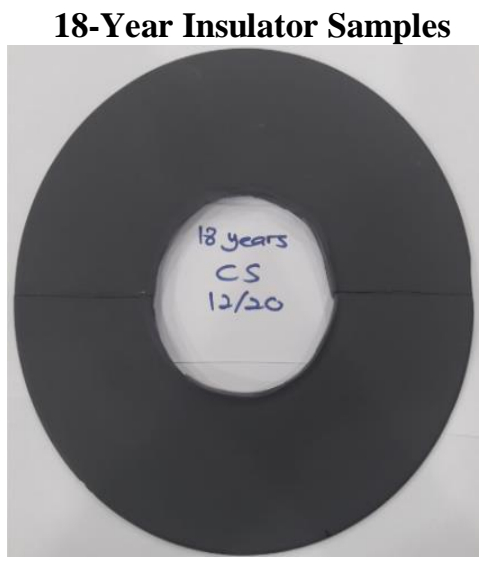

(c) Controlled sample-18-12/20

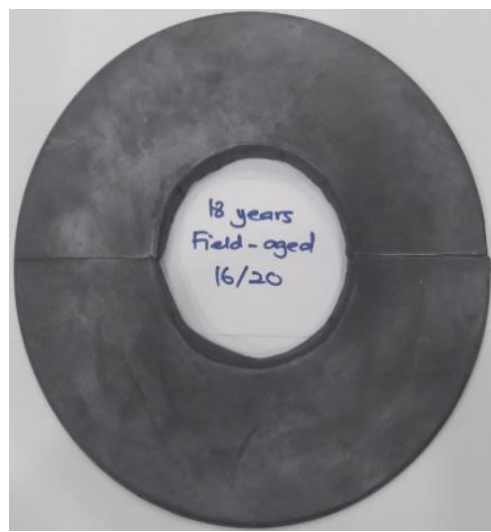

(f) Field-aged-18-16/20

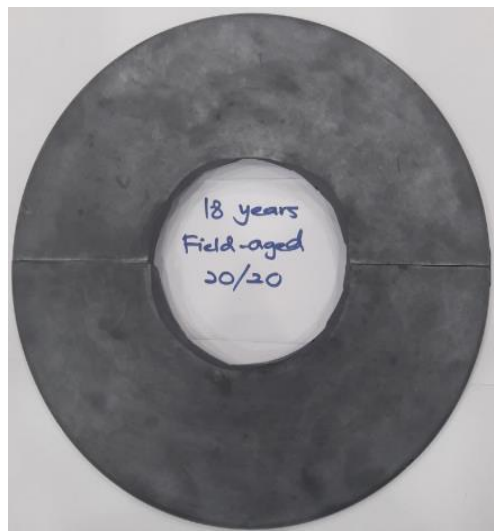

(i) Field-aged-18-20/20

Figure 5. Visual observation of several samples among the groups

\section{CONCLUSION}

From the test results and analysis that have been carried out, it can be observed that the mean arithmetic surface roughness among the controlled sample and field-aged sample have provided an overall view of the whole EPDM rubber insulator with the degradation condition. With almost similar environmental stress condition where they were installed, as the surface roughness data are increased against the age of insulator, these can be as an indicator of the longer field service age of that insulator. On top of that, the surface roughness condition incapable of estimating the field service age of the insulator when there was dissimilar environment stress among them. Indirectly, this condition will also helpful in order to recognize the situation of environmnent stress at the place where they were installed. 


\section{ACKNOWLEDGEMENTS}

The authors are gratefully acknowledged Malaysia Ministry of Higher Education (MOHE), Universiti Teknikal Malaysia Melaka (UTeM) for giving support under research grants of GLuar/STEVIA/2016/FKE-CERIA/I00009 and Universiti Teknologi Malaysia (UTM) for providing facilities in this study under the research grants of vote $12 \mathrm{H} 07$ and 4F751. The authors are also deeply appreciated to the Malaysian national power company, Tenaga Nasional Berhad, TNB (Distribution), Melaka for their assistance in providing the insulator samples used in this study.

\section{REFERENCES}

[1] A. Madi, Y. He, L. Jiang, and B. Yan, "Surface Tracking on Polymeric Insulators Used in Electrical Transmission Lines,” Indones. J. Electr. Eng. Comput. Sci., vol. 3, no. 3, pp. 639-645, 2016.

[2] R. Tripathi, G. Grzybowski, and R. Ward, "Electrical degradation of $15 \mathrm{kv}$ composite insulator under accelerated aging conditions," in 2013 IEEE Electrical Insulation Conference, EIC 2013, 2013, pp. 404-408.

[3] Y. Xiong, S. M. Rowland, J. Robertson, and R. J. Day, "Surface analysis of asymmetrically aged $400 \mathrm{kV}$ silicone rubber composite insulators," IEEE Trans. Dielectr. Electr. Insul., vol. 15, no. 3, pp. 763-770, 2008.

[4] A. A. Salem et al., "The effect of insulator geometrical profile on electric field distributions," Indones. J. Electr. Eng. Comput. Sci., vol. 14, no. 2, pp. 618-627, 2019.

[5] G. Haddad, R. K. Gupta, and K. L. Wong, "Visualization of multi-factor changes in HTV silicone rubber in response to environmental exposures," IEEE Trans. Dielectr. Electr. Insul., vol. 21, no. 5, pp. 2190-2198, 2014.

[6] R. A. Ghunem, "Using the Inclined-Plane Test to Evaluate the Resistance of Outdoor Polymer," IEEE Electrical Insulation Magazine, pp. 16-22, 2015.

[7] I. Ahmadi-Joneidi, A. Majzoobi, A. Shayegani-Akmal, H. Mohseni, and J. Jadidian, "Aging evaluation of silicone rubber insulators using leakage current and flashover voltage analysis," IEEE Trans. Dielectr. Electr. Insul., vol. 20, pp. 212-220, 2013.

[8] A. A. Salem et al., "Proposal of A Dynamic Numerical Approach in Predicting Flashover Critical Voltage," Int. J. Power Electron. Drive Syst., vol. 10, no. 1, pp. 51-58, 2019.

[9] G. Haddad, K. L. Wong, and P. Petersen, "Evaluation of the Aging Process of Composite Insulator based on Surface Charaterisation Techniques and Electrical Method," IEEE Trans. Dielectr. Electr. Insul., vol. 23, no. 1, pp. 311-318, 2016.

[10] B. S. Reddy, S. Prasad, and M. Rajalingam, "Studies on corona degradation of polymeric insulators," in Proceedings of 6th IEEE Power India International Conference, PIICON 2014, 2014, pp. 1-6.

[11] M. K. Moghadam, M. Taheri, S. Gharazi, M. Keramati, M. Bahrami, and N. Riahi, "A study of composite insulator aging using the tracking wheel test,” IEEE Trans. Dielectr. Electr. Insul., vol. 23, no. 3, pp. 1805-1811, 2016.

[12] R. Saldivar-Guerrero, R. Hernández-Corona, F. A. Lopez-Gonzalez, L. Rejón-García, and V. Romero-Baizabal, "Application of unusual techniques for characterizing ageing on polymeric electrical insulation," Electr. Power Syst. Res., vol. 117, pp. 202-209, 2014.

[13] Y. Khan, "Degradation of High Voltage Polymeric Insulators in Arid Desert's Simulated Environmental Conditions.," Am. J. Eng. Appl. Sci., vol. 2, no. 2, pp. 438-445, 2009.

[14] N. Dhahbi-megriche and A. Beroual, "Time - frequency analyses of leakage current waveforms of high voltage insulators in uniform and non-uniform polluted conditions," IET Sci. Meas. Technol., vol. 9, no. 8, pp. 945-954, 2015.

[15] W. Song et al., "Aging characterization of high temperature vulcanized silicone rubber housing material used for outdoor insulation," IEEE Trans. Dielectr. Electr. Insul., vol. 22, no. 2, pp. 961-969, 2015.

[16] Wikipedia, "Surface roughness," https://en.wikipedia.org/wiki/Surface_roughness, 2018.

[17] J. P. Reynders, I. R. Jandrell, and S. M. Reynders, "Review of aging and recovery of silicone rubber insulation for outdoor use," IEEE Trans. Dielectr. Electr. Insul., vol. 6, no. 5, pp. 620-631, 1999.

[18] E. S. Gadelmawla, M. M. Koura, T. M. A. Maksoud, I. M. Elewa, and H. H. Soliman, "Roughness parameters," vol. 123, pp. 133-145, 2002.

[19] G. Haddad, K. L. Wong, and P. Petersen, "Evaluation of the hydrophobic property of composite insulators using Dynamic Drop Test," in Proceedings of the International Symposium on Electrical Insulating Materials, 2014, pp. 280-283.

[20] M. Amin and S. Amin, "Aging Research on SIR and TPE Insulators (An Overview)," Rev. Adv. Mater. Sci., vol. 36, pp. 29-39, 2014.

[21] M. Amin and M. Salman, "Aging of Polymeric Insulators (An Overview)," Rev. Adv. Mater. Sci., vol. 13, pp. 93-116, 2006.

[22] P. S. Mann, Introductory Statistics, Eighth Edi. Singapore: John Wiley \& Sons Singapore Pte. Ltd., 2013.

[23] "PVN Polymer Station Class Arresters," Hi-Tension News, no. 1051, pp. 1-4, 1993.

[24] "Electrical insulating materials used under severe ambient conditions - Test methods for evaluating resistance to tracking and erosion (BS EN 60587:2007)," vol. 3. pp. 1-14, 2007.

[25] Mitutoyo, "SURFTEST SJ-410 Series," M3 Solution Centers, no. 2196, America, pp. 1-12, 2015.

[26] "Google Earth Pro Version 7.3," https://earth.google.com/download-earth.htm, 2018. 


\section{BIOGRAPHIES OF AUTHORS}

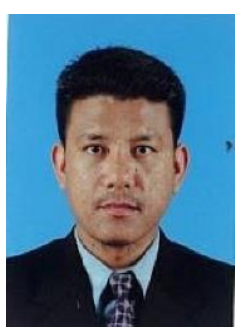

Asri Din (A. Din) was born in Melaka, Malaysia on June 11, 1977. He has received the B. Eng in Electrical and Electronics from Universiti Teknologi Malaysia in 2000 and M. Eng in Electrical Energy and Power System from Universiti Malaya, Malaysia in 2008. He is a senior lecturer of Universiti Teknikal Malaysia Melaka and has been working there since December 2002. Prior to this, he used to work as a Product Engineer at Ceemax Technology in Melaka from 2000 to 2002. Currently he is undergoing his PhD study on the outdoor polymer insulator degradation performance monitoring at the Institute of High Voltage and High Current (IVAT) under School of Electrical Engineering, Faculty of Engineering, Universiti Teknologi Malaysia.

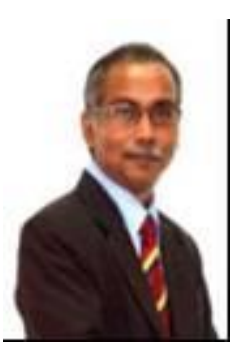

Dr. Mohamed Afendi Mohamed Piah (M.A.M. Piah) is an associate professor at School of Electrical Engineering, Faculty of Engineering, Universiti Teknologi Malaysia and a fellow member of the Institute of High Voltage and High Current (IVAT). He is also a Signatory of High Voltage Testing accreditation lab of ISO/IEC 17025. He received the B.Elect. Eng. degree from Universiti Teknologi Malaysia in 1986, M.Sc in Power System from University of Strathclyde, UK in 1990 and $\mathrm{PhD}$ in High Voltage Engineering from Universiti Teknologi Malaysia in 2004. He was appointed as an assistant director (Test and Calibration Division) of IVAT from 1996-2000 and Deputy Director of IVAT from 2007-2009. He has been involved in testing and calibration of high voltage equipments. His research interests include high voltage insulation diagnostic and co-ordination, electrical discharges, polymer nanocomposites insulating materials and insulator condition monitoring.

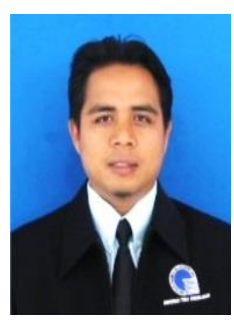

Dr. Abdul Rahim Abdullah (A.R. Abdullah) was born in Kedah, Malaysia on 1979. He received his B. Eng., Master Eng., PhD Degree from Universiti Teknologi Malaysia in 2001, 2004 and 2011 in Electrical Engineering and Digital Signal Processing respectively. He is currently an Associate Professor at the Department of Electrical Engineering, Deputy director of Center for Edu- Tourism and Chief of Advanced Digital Signal Processing (ADSP) Lab, Universiti Teknikal Malaysia Melaka (UTeM).

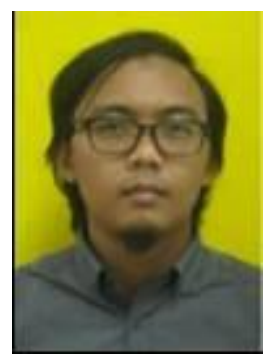

Nur Faizal Kasri (N. F. Kasri) is a PhD student at School of Electrical Engineering, Faculty of Engineering, Universiti Teknologi Malaysia and a fellow member of the Institute of High Voltage and High Current (IVAT). He received the B. Mechatronic. Eng. degree from Universiti Teknologi Malaysia in 2011, M. Sc in Elect. Eng. also from Universiti Teknologi Malaysia in 2014. He was appointed as a part time lecturer in UiTM Pasir Gudang from 2014-2015 before pursuing his $\mathrm{PhD}$ study. He has been involved in testing and calibration of high voltage equipment, insulation diagnostic and consultancy project with Tenaga Nasional Berhad and Research (TNBR). His research interests include high voltage insulation diagnostic and coordination, electrical discharges, polymer nanocomposites insulating materials and insulator condition monitoring and food technology process. 